\title{
Facilitated Peer Mentorship to Support Aging Research: A RE-AIM Evaluation of the CoMPAdRE Program
}

\author{
Ruth M. Masterson Creber, PhD, MSc, RN, * (1) Matthew R. Baldwin, MD, MS, ${ }^{\dagger}$ (1) \\ Patrick J. Brown, PhD, ${ }^{\dagger \neq}$ Maya K. Rao, MD, ${ }^{\dagger}$ Parag Goyal, MD, ${ }^{\S}$ Scott Hummel, MD, ${ }^{q}$ \\ John A. Dodson, MD," Stephen Helmke, MPH, RDCS, ** and Mathew S. Maurer, MD**
}

See related editorial by High et al. in this issue.

BACKGROUND: The need for mentorship in aging research among postdoctoral trainees and junior faculty across medical disciplines and subspecialties is increasing, yet senior personnel with expertise in aging are lacking to fulfill the traditional dyadic mentorship role. Facilitated peer mentorship is grounded in collaborative work among peers with the guidance of a senior mentor.

METHODS AND RESULTS: We evaluated the Columbia University Mentor Peer Aging Research (CoMPAdRE) program, an interprofessional facilitated peer mentorship program for early stage investigators, using the Reach Effectiveness Adoption Implementation and Maintenance framework (RE-AIM). Reach: A total of 15 participants, of which $20 \%$ were women, from five states and across six medical specialties participated. Effectiveness: Participants published 183 papers, of which more than 20\% were collaborative papers between CoMPAdRE mentees or mentees-mentor. Participants reported developing skills in negotiation, navigating the academic role, organizing a seminar, management, and leadership over the course of the program. According to the qualitative findings, the most important components of the program included alignment

From the *Department of Healthcare Policy \& Research, Division of Health Informatics, Weill Cornell Medicine Center, New York, New York; ${ }^{\dagger}$ Department of Medicine, Columbia University Vagelos College of Physicians and Surgeons, New York, New York; ${ }^{\circ}$ Division of Geriatric Psychiatry, New York State Psychiatric Institute, Columbia University College of Physicians and Surgeons, New York, New York; ${ }^{\S}$ Department of Medicine, Weill Cornell Medicine, New York, New York; "University of Michigan and Ann Arbor Veterans Affairs Health System, Ann Arbor, Michigan; "Leon H. Charney Division of Cardiology, Department of Medicine, Division of Healthcare Innovation and Delivery Science, Department of Population Health, New York University School of Medicine, New York, New York; and the **Clinical Cardiovascular Research Laboratory for the Elderly, Allen Hospital of New YorkPresbyterian, Columbia University Irving Medical Center, New York, New York.

Address correspondence to Ruth M. Masterson Creber, PhD, MSc, RN, 425 East 61st Street, Suite 301, Room 323, New York, NY 10065 ; E-mail: rmc2009@med.cornell.edu

DOI: 10.1111 /jgs.15792 around the aging, learning from national leaders, developing leadership skills and career networking. Adoption: Individual-level factors included selecting participants with a research track record, willingness to sign a compact of commitment and involvement in shaping the program. An institutional-level factor that facilitated program adoption included strong commitment from department leaders. Implementation: The program cost $\$ 3,259$ per participant. Maintenance: CoMPAdRE is being maintained and currently incorporating a second cohort of mentees.

CONCLUSION: This RE-AIM evaluation provides lessons learned and strategies for future adoption, implementation, and maintenance of an aging-focused facilitated peer mentorship program. J Am Geriatr Soc 67:804-810, 2019.

Key words: mentoring; aging; older adults; geriatrics; academic medicine; early career; faculty development; peer group; implementation science

$\mathrm{T}$ he traditional dyadic model between a mentee and senior mentor is the prevailing mentorship model at most academic medical centers. ${ }^{1,2}$ Challenges of this traditional model include difficulty identifying a mentor, maintaining the relationship over time, and considerable investment on the part of both partners. ${ }^{3}$ Given the scarcity of primary mentors with expertise in aging research, overreliance on the dyadic mentorship model is particularly detrimental to early stage investigators, especially women and minority faculty, ${ }^{4,5}$ in aging research.

Novel mentoring models are needed to meet the current needs of interprofessional junior faculty members who study and treat complex age-related diseases and phenotypes. ${ }^{6-9}$ One alternative is a facilitated peer mentorship model that includes elements of both dyadic and peer mentoring models. ${ }^{10}$ The peer mentorship component of this model provides a forum for mentees to discuss common needs and challenges that may 
have not been addressed in the dyadic mentorship relationship including work-life balance, career advancement, negotiation, promotion, and collaborative research development. Peers effectively mentor each other through the process of brainstorming and modeling solutions to shared challenges, and in doing so they may develop a sense of belonging that in turn leads to greater career satisfaction.

The Columbia Mentor Peer Aging Research Program (CoMPAdRE) was developed to address the need for facilitated peer mentorship that complements and supplements dyadic mentorship for early career clinical investigators with a focus on aging research. Instead of embarking on a quest for the perfect mentor, the underlying tenet of CoMPAdRE is for individuals to benefit from pursuing a strategy of being the "perfect" protégé-mentee, and to build a network of developmental relationships. ${ }^{3}$ At the completion of the 2-year CoMPAdRE program, we evaluated the program using the implementation science of Reach Effectiveness Adoption Implementation Maintenance (RE-AIM) framework.

\section{METHODS}

\section{Participants}

Fifteen early career mentees at the postdoctoral, instructor, or assistant professor levels participated in CoMPAdRE between March 2016 and May 2018 at Columbia University Medical Center. Participants were selected from across the country if they had an established mentorship from the facilitating senior mentor (M.S.M.) and had an interest and/or track record in patient-oriented research with older adults.

\section{Program Description}

The program was structured around eight full-day retreats held every 4 months. These day-long retreats included (1) workshops focused on strategic key skills/knowledge necessary for success in academic medicine, (2) forums to share career aspirations and research interests, (3) time to develop collaborations, and (4) networking and mentorship from leaders in aging research. Sessions consisted of didactic sessions on career development and advancement, interactive discussions with leaders in aging research about their careers and the state of aging research, peer-to-peer discussions to address career challenges and develop collaborative investigations, and one-on-one mentorship discussions with the facilitating mentor and visiting faculty. Each participant also signed a compact of commitment requesting that mentees commit to attending more than $75 \%$ of the sessions over 2 years (Supplementary Table 1 ).

\section{Program Development}

Six months before to the first CoMPAdRE retreat, the facilitating mentor and a program administrator solicited suggestions from participants for speakers, career- and researchrelated topics, and optimal dates, duration, and frequency of the retreats. The first five CoMPAdRE retreats were structured around the highest ranked topics and speakers. To gain experience in organizing a day-long workshop, participants were asked to organize the last three CoMPAdRE sessions around self-appointed topics.
There was consensus that an all-day program that met three times a year was optimal. The structure for each session included breakfast, followed by a brief presentation by the facilitating mentor on participants' accomplishments including publications in the last 3 months, grants submissions and awards, academic milestones (eg, promotions, awards, and invited lectures), and personal life events (eg, marriage, children). A typical morning session began with didactics, discussion, and small-group work for 1.5 hours that focused on one of the career development topics that participants had initially selected, followed by the invited faculty member's seminar. Seminars focused on how the faculty member's career developed, including successes and failures, and suggestions for advancement, enjoyment, and scientific areas that they thought were promising and novel. Subsequently, participants had further facilitated discussions with visiting faculty about career and research advancement. The afternoon session was followed by dinner together, with the goal of further facilitating relationship development and networking.

\section{RE-AIM Implementation Science Framework}

The RE-AIM model is an implementation science framework for evaluation that focuses on the reach of the intervention to a representative proportion of the target population; effectiveness of a program on specific outcomes; adoption of the program in a specified setting; and details of program implementation and maintenance. ${ }^{11,12}$

\section{Data Sources and Measurements}

We assessed program effectiveness based on (1) participant publications, grants, and career advancements achieved during the 2-year program, and (2) participant feedback from a structured survey that we administered at the end of the 2 -year program. We ascertained participant publications and classified them as first author, senior author, and/or coauthored with a CoMPAdRE participant. We ascertained participant grants from NIH RePORTER. Before each CoMPAdRE retreat, participants reported recent honors/ awards, grant submissions, and conference presentations. At the end of the program, we used Qualtrics Survey software to administer a 16-item survey to assess improvement in grantsmanship, organizational, leadership, and research skill development on a 7-item response Likert scale. The survey included solicited open-ended feedback about the strengths and weaknesses of CoMPAdRE, challenges to participation, and aspects of the program that might need to be changed or improved. The study was approved by the Columbia institutional review board (Protocol AAAR8784).

\section{Data Analysis}

We report standard descriptive statistics for the quantitative data. The qualitative data from the open-ended questions of the Qualtrics Survey were analyzed by directed content analysis. This method uses factors from a relevant theory to guide data collection and analysis. A codebook of themes based on the factors in the RE-AIM framework was created. Qualitative data were analyzed using the codebook, and subthemes were created when appropriate. ${ }^{13,14}$ 


\section{RESULTS}

\section{Reach}

There were 15 participants from seven academic programs representing five states (Table 1). Overall, $20 \%$ were women, $25 \%$ were Asian, and $7 \%$ Hispanic. At the start of the program, $67 \%$ of participants were faculty at the rank of assistant professor or instructor, $33 \%$ were trainees, and $60 \%$ of participants were federally funded (T32 programs, K23 awards, and Paul B. Beeson Emerging Leaders Career Development Award in Aging awards).

\section{Effectiveness}

CoMPAdRE participants published 183 publications, of which $20 \%$ were coauthored between CoMPAdRE mentees and the mentor. Mentees were awarded a total of $10 \mathrm{~K}$ - or R-level awards as principal investigators (PIs). At the completion of the program, $93 \%$ of participants were federally funded as principal investigators on either a K- or R-level award.

Nearly all participants $(91 \%)$ agreed or strongly agreed that CoMPAdRE supported their organizational and leadership skills development, particularly in regard to negotiation skills, navigating their academic role, and promotion

\section{Table 1. Reach and effectiveness of CoMPAdRE}

Reach and participant characteristics at baseline (May 2016) $(n=15)$

\begin{tabular}{|c|c|}
\hline Age (mean $\pm S D$ ), y & $36( \pm 3.4)$ \\
\hline Female sex (\%) & $3(20)$ \\
\hline \multicolumn{2}{|l|}{ Race/Ethnicity (\%) } \\
\hline White & $10(66)$ \\
\hline Asian & $4(25)$ \\
\hline Hispanic/Latino & $1(7)$ \\
\hline \multicolumn{2}{|l|}{ Highest academic degree (\%) } \\
\hline $\mathrm{PhD}$ & $4(27)$ \\
\hline MD & $11(73)$ \\
\hline \multicolumn{2}{|l|}{ Clinical specialty (\%) } \\
\hline Cardiology & $9(60)$ \\
\hline Nephrology & $1(7)$ \\
\hline Pulmonary/Critical care & $1(7)$ \\
\hline Psychology & $2(13)$ \\
\hline Statistics & $1(7)$ \\
\hline Nursing & $1(7)$ \\
\hline Mentees with federal funding at baseline (\%) & $10(66)$ \\
\hline K23 & $6(40)$ \\
\hline T32 & $2(13)$ \\
\hline Beeson K23 Award & $2(13)$ \\
\hline \multicolumn{2}{|c|}{ Effectiveness: peer-reviewed articles published, $n=183$} \\
\hline First authored & $76(42)$ \\
\hline Senior authored & $40(22)$ \\
\hline $\begin{array}{l}\text { Published by two or more CoMPAdRE } \\
\text { participants }\end{array}$ & $9(5)$ \\
\hline $\begin{array}{l}\text { Published by a CoMPAdRE participant and } \\
\text { mentor }\end{array}$ & $31(17)$ \\
\hline \multicolumn{2}{|l|}{ Effectiveness: grantsmanship (\%) } \\
\hline Principal investigator awarded federal grants & $10(66)$ \\
\hline GEMSSTAR R03 & $2(13)$ \\
\hline K99/R00 & $1(7)$ \\
\hline KL2 & $1(7)$ \\
\hline $\mathrm{R} 21$ & $3(20)$ \\
\hline R01 (or Veterans Affairs equivalent) & $3(20)$ \\
\hline
\end{tabular}

(Figure 1A). Participants reported that CoMPAdRE especially supported the development of research and grantsmanship skills in relation to interacting with peers and reviewers, and less so with learning about the geriatrics research literature or grant writing (Figure 1B). Nearly all participants agreed or strongly agreed that CoMPAdRE provided a forum to develop peer relationships, research collaboration, and a national network (Figure 1C).

\section{Qualitative Findings}

Four primary themes emerged from the open-ended postimplementation survey that are described here: alignment around aging, learning from national leaders, leadership and executive skills, and career networking and promotion.

\section{Alignment Around Aging}

A core component of this program was the alignment of "like-minded individuals across multiple disciplines where aging research is the common thread." The focus on aging brought together "peers with expertise in all different areas, but a common passion for geriatrics." Bringing together a group of individuals from different medical disciplines and states who shared a research focus on aging provided a community that helped each participant advance his or her career. One participant noted that it helped stave off the "existential crisis" that is common when facing the early academic medicine career challenges at institutions that do not have robust aging research programs with strong mentorship in place.

\begin{abstract}
"CoMPAdRE provides a research network to discuss and discover new ideas for investigation. The fact that medical subspecialists with different backgrounds come together with a shared interest in gerontology opens a younger investigator's perspective on aging research beyond the small group of investigators that a young investigator is likely to spend most of her/his time with."
\end{abstract}

\section{Learning from National Leaders}

Overall, there were 20 visiting faculty ( 8 from Columbia and 12 from other institutions) of diverse areas of scholarship who described their career trajectories, presented their paths of scientific discovery, and facilitated peer mentorship. Inviting leaders in gerontology gave participants the rare opportunity to speak with and learn from them directly about unique professional mechanisms for acquiring data and specific aging-related grant mechanisms.

\section{"It's also been a privilege to get to hear from all the incredible speakers and because of the small size to get an opportunity to interact with them as well. I particularly appreciate that there were several highly accomplished women speakers."}

A unique aspect of the program was having highly successful visiting faculty who were willing to discuss their career paths-including successes and failures-and to have 
(A) Organizational \& Leadership Skill Development

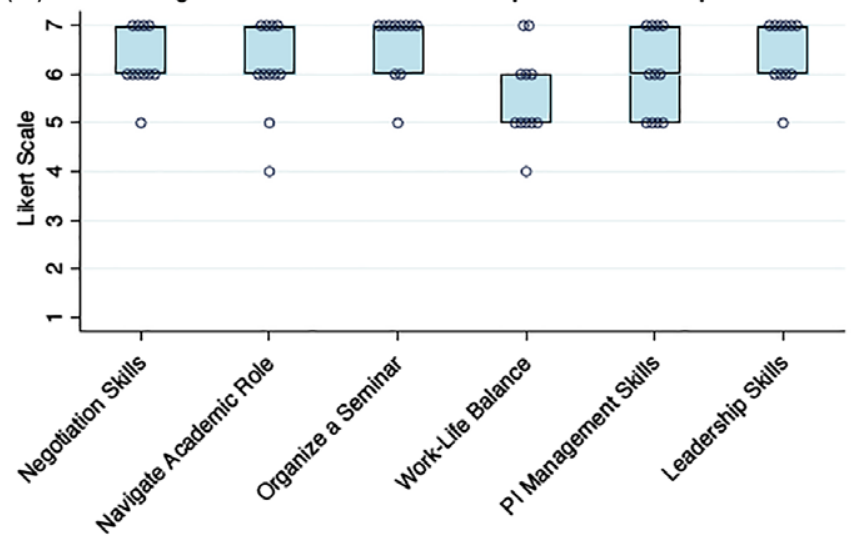

(B)

Research \& Grantsmanship Skill Development

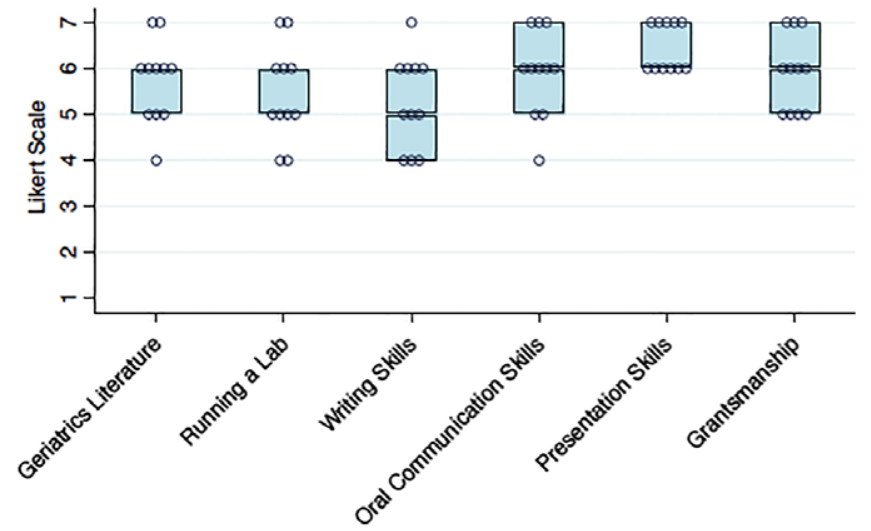

(C) Research Network Development

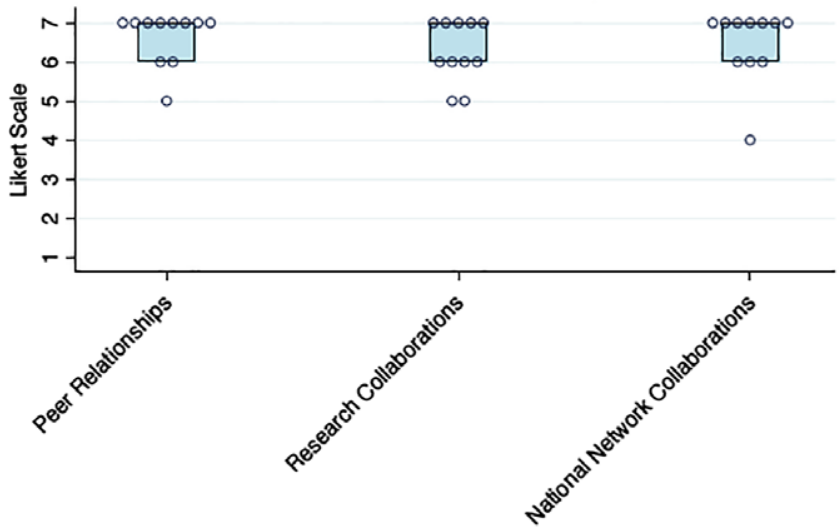

Figure 1. Ratings of how CoMPAdRE peer mentorship supported (A) organizational and leadership skill development, (B) research and grantsmanship skill development, and $(\mathrm{C})$ research network development. Boxes represent median and interquartile ranges, and dots represent individual participant ratings. Likert scale: Strongly disagree (1), Disagree (2), Somewhat disagree (3), Neither agree nor disagree (4), Somewhat agree (5), Agree (6), Strongly agree (7). PI, principal investigator.

the structure of "small groups with the ability to plan programs focused on individual needs."

"Hearing from leading gerontologic researchers (who are known for success) about both their success, and more importantly, their failures during their illustrious careers belps alleviate the stress of obstacles and failures in one's own career."

\section{Leadership and Executive Skills}

A core component of the program was teaching early career trainees about leadership and executive skills that many participants noted was missing from their training.

"CoMPAdRE provides a forum to formally teach leadership and executive skills. These skills, that make up the core of graduate business school education, are not taught during doctoral or postdoctoral training in medicine. However, these skills are likely just as necessary for PI's [principal investigators] and other leaders in academic medicine as they may be in the business world. Having formal instruction and informal seminars about leadership and executive skills belp early stage investigators progress to being effective PI's."

\section{Career Networking and Promotion}

CoMPAdRE was described as "widely applicable to all levels of training and career paths." The inclusion of peer mentees from across institutions facilitated building a network that was instrumental for mentees who made transitions from training to faculty and advancing faculty roles during the tenure of the program.

"It is so important to have friends and colleagues outside of one's home institution in order to broaden perspectives and find other co-investigators for multi-site studies.”

Being affiliated with CoMPAdRE facilitated sponsorship. Participants reported that the program helped with the promotion process by supporting national reputation and helped to forge collaborations with other mentees and visiting faculty.

\section{Adoption}

Both individual and institutional aspects facilitated the successful adoption of CoMPAdRE. All participants had a track record of clinical research experience in aging, 
signed a compact to participate in the 2-year program, and had a high level of buy-in because they themselves chose the topics to address at each session. Institutionallevel factors that supported the adoption of CoMPAdRE program included minimal financial commitment because the CoMPAdRE programming costs were supported by a National Institute on Aging (NIA) K24 award (PI: Maurer), division and department chiefs agreeing to protect participants' time away from work to participate in the day-long retreats, and travel expenses for nonlocal participants.

\section{Implementation}

We identified themes and lessons learned related to the implementation of the program based on participants' feedback (Table 2). Of note the CoMPAdRE program required a facilitating mentor as well as an administrator to support the logistics. Participants valued learning through interacting with other early stage investigators from diverse medical disciplines and subspecialties (eg, psychology, nursing, informatics, statistics). Participants preferred a balance of male and female speakers from outside of the hosting

Table 2. Adoption, implementation, and maintenance: lessons learned for future implementation

\begin{tabular}{|c|c|}
\hline Selection criteria & $\begin{array}{l}\text { - It was beneficial to include trainees who already obtained a } \mathrm{K} \text { award as well as those } \\
\text { who planned to submit a } \mathrm{K} \text { award. } \\
\text { - Participants who had not written a K award reported learning a lot from those who had } \\
\text { been awarded one. }\end{array}$ \\
\hline & $\begin{array}{l}\text { "I think it would have been nice to see more women in the peer group. . . I I really } \\
\text { appreciated the effort to bring women speakers in who were all highly } \\
\text { accomplished." }\end{array}$ \\
\hline & $\begin{array}{l}\text { "There can also be challenges to the group being multidisciplinary, including } \\
\text { struggling to form productive peer relationship if you are in an 'underrepresented" } \\
\text { discipline." }\end{array}$ \\
\hline One-on-one time & $\begin{array}{l}\text { - Participants wanted to have more one-on-one time with the visiting faculty to build } \\
\text { those relationships and get to know them personally. }\end{array}$ \\
\hline $\begin{array}{l}\text { Timing in tandem with a conference } \\
\text { to minimize travel }\end{array}$ & $\begin{array}{l}\text { - For those who are traveling for the retreats one suggestion was to hold them in } \\
\text { tandem with a national conference and getting the program approved for CMEs. }\end{array}$ \\
\hline
\end{tabular}

"At the least, it seems like we could try to get the [geographically local] people together or potentially try to arrange something at meetings such as AGS."

Participant involvement

Communication between meetings
- Facilitating more of the speakers to give talks on their current research so that it was clear where points of collaboration may be.

- Tapping the resources within the group also enables more of a shared understanding of methods, consistent outcome measurement and methods for measurement that are applicable to all participants.

- New ideas include inviting basic scientists to present to broaden perspectives and knowledge about basic scientific principles and how they inform a translational perspective.

- Some modifications were suggested moving forward with the program included more electronic communication between meetings:

"It would be great to continue to have some electronic interaction and way of keeping up with the group as a whole. . . . I know it's a challenge with people being all over the country and at different institutions to consider something in person."

- Moving forward one suggestion is to focus a retreat topic exclusively on co-writing grants so more collaborative grants can come from this group.

"It would be really helpful to have opportunities to come together for day-long grant writing or manuscript writing sessions together to carve out time to make that happen." "I wasn't in the right stage of my career to write a collaborative R01-I needed to get my first one."

Addressing barriers
- For individuals, the largest reported barrier to collaboration was balancing that with competing clinical, administrative and research demands. 
institution because it gave them the opportunity to discuss sensitive topics like promotion and tenure. Participants reported high satisfaction with being able to interact personally with internationally recognized leaders in aging research that in some instances led to publications and grant applications with these leaders.

Funding for the implementation of the program was provided through a NIA K24 mentoring grant. In all, the program functioned for 2 years at a total cost of $\$ 48$ 898 , equivalent to $\$ 3,259$ per participant. The top-three areas for spending included travel for participants and faculty $(37 \%)$, renting space and lodging for out-of-town participants and guest faculty $(27 \%)$, and catering $(17 \%)$ (Supplementary Figure 1).

\section{Maintenance}

The development of the program around the needs of the CoMPAdRE participants was the most important dimension to support maintenance of the program. In this case, supporting mentees in their transitions from early stage investigators to independent investigators was the primary aim. Participants noted a strong need to develop administrative and management skills, and mentoring skills as they themselves become mentors. Topics that participants wanted more of in the future included (1) continued leadership and executive training, (2) reviewing grants collaboratively and with strategic scheduling to provide one another with feedback at least 2 months before submission deadlines, and (3) having peer participants present more of their own work to generate new perspectives within the peer mentorship group, and to be able to think through the development of grant ideas together. Overall, CoMPAdRE provided a strong peer network such that participants chose to continue the program after the last session in May 2018. One of the primary reasons was the ongoing opportunity to connect with peers at other universities:

"I could foresee that this network would continue as we start to mentor our own trainees, and we can put these trainees in touch with our CoMPAdRE peers and perhaps their trainees."

\section{DISCUSSION}

An evaluation of the CoMPAdRE facilitated peer mentorship program using the RE-AIM framework provides insights for dissemination to other institutions. The principal findings of this evaluation were that the CoMPAdRE facilitated peer mentorship program supported the development of participants' executive skills and overall career advancement toward becoming independent clinical investigators. The program expanded and strengthened participants' interprofessional networks in aging. In turn, participants published collaborative research projects, secured faculty jobs, and were promoted.

Leadership in academic medicine lacks diversity, particularly among women and racial and ethnic minorities. ${ }^{15,16}$ Peer mentorship may be of particular benefit to minority groups by facilitating a professional network that is requisite to obtaining a national reputation and academic promotion. ${ }^{4}$ Facilitated peer mentorship programs may be one mechanism to address the disparities that exist at the associate and full professor levels at most academic medical centers and major universities. ${ }^{17,18}$

The facilitated peer mentorship model also benefits the facilitating mentor by providing a regularly scheduled opportunity to meet with mentees both collectively and individually during the 1-day retreats. In CoMPAdRE, the facilitating mentor was able to provide mentorship to a larger cadre of mentees than would be feasible with a traditional dyad model of mentorship. ${ }^{9}$ Although the facilitating mentor continued to provide one-on-one feedback to mentees, the feedback was focused on specific projects rather than broader mentorship topics that were addressed in the CoMPAdRE sessions. Our finding is in contrast to a systematic literature review that concluded a significant time commitment by mentors is a barrier to creating peer mentorship programs. ${ }^{19}$

\section{Strengths and Limitations}

The geographic diversity of participants was both a strength and a weakness of the program. The geographic diversity provided a more diverse perspective on career development and research challenges, and it created an opportunity for cross-institution networking, and yet it also made it more expensive (due to airfare and hotel costs) and more complex to schedule the retreats. A limitation of the first CoMPAdRE cohort was a lack of gender and racial/ethnic diversity; however, this was addressed in the second CoMPAdRE cohort.

An expected challenge of the program was attrition of active attendance at the sessions (about 13\%). A few attendees were not able to attend as frequently because of the travel and other work-life demands. To adjust for attrition after 2 years, we invited new participants into the second CoMPAdRE cohort.

One of the original hypotheses of the program was that it would support multi-PI R01 grants; however, there were no multi-PI R01s submitted in the first 2 years of the program. At the start of CoMPAdRE, none of the participants had an R01. Thus grantsmanship skill development focused on either obtaining either a $\mathrm{K}$ or the first R01 award, rather than multi-PI awards. In addition, all of the reported effectiveness outcomes (ie, grants and publications) associated with the CoMPAdRE program are not necessarily due to skills and networks created by the program.

A typical challenge for peer mentorship programs is that they are usually funded through time-restricted funds ${ }^{19}$ that limits long-term sustainability. The CoMPAdRE program could be implemented for less if mentees were within the same geographic area (obviating the need for travel costs). Additional savings could also accrue through local access to more economical food and venue choices.

\section{CONCLUSION}

Advancing aging research that addresses the unmet needs of older adults with complex phenotypes from heterogeneous populations requires interdisciplinary collaboration between faculty members who are traditionally siloed by medical specialty or discipline at large academic medical centers. The 
CoMPAdRE program shows that a facilitated peer mentorship program can bring together diverse individuals to collaborate on high-quality multidisciplinary aging research, and in turn, collectively promote career advancement. A facilitated peer mentorship program focused on aging might be most effective for participants from institutions that do not already offer a comprehensive geriatric medicine training program, of which there are few. ${ }^{21}$ For those that already have such a program, this might augment the resources already being provided and extend the reach of the program. Topically focused facilitated peer mentorship programs could be expanded to many other research areas that require interprofessional collaboration including immunology, neuroscience, and minority health, among others. As such, there is strong potential for broad generalizability and potential to be an important and cost-effective resource for early career faculty members. A cost-effectiveness analysis was conducted at the University of California, San Diego, National Center for Academic Medicine and found that peer mentorship programs are cost effective. ${ }^{20}$

\section{ACKNOWLEDGMENTS}

We would like to acknowledge the administrative assistance of Dr. Sergio Teryua and Samantha Guadalupe from the Clinical Cardiovascular Research Laboratory for the Elderly, Allen Hospital of New York Presbyterian, Columbia University Irving Medical Center. We would also like to thank all of the CoMPAdRE members for their commitment to the facilitated mentorship program. Finally, we would like to acknowledge the guest faculty (named in Supplementary Table 2), most of whom volunteered their time to come and speak to the CoMPAdRE participants.

Financial Disclosure: Mid-Career Mentoring Award in Geriatric Cardiology, K24: AG036778 (PI: Maurer).

National Institutes of Health/National Institute of Nursing Research, R00: NR016275 (PI: Masterson Creber).

National Institutes of Health/National Institute on Aging, K23: AG045560 (PI: Baldwin).

National Institute for Mental Health, K23: MH099097 (PI: Brown).

National Institutes of Health/National Institute on Aging, Patient-Oriented Career Development Award, K23: AG052463 (PI: Dodson).

National Institutes of Health/National Institute on Aging, R03:AG053294 (PI: Rao).

National Institutes of Health/National Institute on Aging, R03: AG056446 (PI: Goyal).

Veterans Administration, 5I01 CX001636 (PI: Hummel).

Conflict of Interest: All authors have declared no conflict of interest for this article.

Author Contributions: Ruth M. Masterson Creber: drafting of manuscript, data collection, and data analysis. Matthew R. Baldwin: data collection, data analysis, and substantive edits to manuscript. Patrick J. Brown: data collection, data analysis, and substantive edits to manuscript. Maya K. Rao, Parag Goyal, Scott Hummel, and John A. Dodson: substantive edits to manuscript. Stephen Helmke: data collection and substantive edits to manuscript. Mathew S. Maurer: funding, study design, data collection, data analysis, and substantive edits to manuscript.

Sponsor's Role: None.

\section{REFERENCES}

1. Kashiwagi DT, Varkey P, Cook DA. Mentoring programs for physicians in academic medicine: a systematic review. Acad Med. 2013;88(7):1029-1037.

2. White HK, Buhr GT, Pinheiro SO. Mentoring: a key strategy to prepare the next generation of physicians to care for an aging America. J Am Geriatr Soc. 2009;57(7):1270-1277.

3. Harvard Business School. Beyond the myth of the perfect mentor: building a network of developmental relationships. Harv Bus Rev. 1998;1-12.

4. Varkey P, Jatoi A, Williams A, et al. The positive impact of a facilitated peer mentoring program on academic skills of women faculty. BMC Med Educ. 2012;12:14.

5. Johnson JC, Williams B, Jayadevappa R. Mentoring program for minority faculty at the University of Pennsylvania School of Medicine. Acad Med. 1999;74(4):376-379.

6. Maurer MS. Heart failure with a normal ejection fraction (HFNEF): embracing complexity. J Card Fail. 2009;15(7):561-564.

7. Maurer MS, Mancini D. HFpEF: is splitting into distinct phenotypes by comorbidities the pathway forward? J Am Coll Cardiol. 2014;64(6):550-552.

8. Inouye SK, Studenski S, Tinetti ME, Kuchel GA. Geriatric syndromes: clinical, research and policy implications of a core geriatric concept. J Am Geriatr Soc. 2007;55(5):780-791

9. Pololi LH, Knight SM, Dennis K, Frankel RM. Helping medical school faculty realize their dreams: an innovative, collaborative mentoring program. Acad Med. 2002;77(5):377-384.

10. DeCastro R, Sambuco D, Ubel PA, Stewart A, Jagsi R. Mentor networks in academic medicine: moving beyond a dyadic conception of mentoring for junior faculty researchers. Acad Med. 2013;88(4):488-496.

11. Glasgow RE, Vogt TM, Boles SM. Evaluating the public health impact of health promotion interventions: the RE-AIM framework. Am J Public Health. 1999;89(9):1322-1327.

12. Glasgow RE, Klesges LM, Dzewaltowski DA, Estabrooks PA, Vogt TM. Evaluating the impact of health promotion programs: using the RE-AIM framework to form summary measures for decision making involving complex issues. Health Educ Res. 2006;21(5):688-694.

13. Hsieh HF, Shannon SE. Three approaches to qualitative content analysis. Qual Health Res. 2005;15(9):1277-1288.

14. Graneheim UH, Lundman B. Qualitative content analysis in nursing research: concepts, procedures and measures to achieve trustworthiness. Nurse Educ Today. 2004;24(2):105-112.

15. Yedidia M, Bickel J. Why aren't there more women leaders in academic medicine? The views of clinical department chairs. Acad Med. 2001;76(5):453-465.

16. Lewis D, Paulsen E. Proceedings of the Diversity and Inclusion Innovation Forum: Unconscious Bias in Academic Medicine. Washington, DC: Association of American Medical Colleges; 2017.

17. American Association of Medical Colleges (AAMC). Striving Toward Excellence: Faculty Diversity in Medical Education. Washington, DC: AAMC; 2009.

18. Efstathiou JA, Drumm MR, Paly JP, et al. Long-term impact of a faculty mentoring program in academic medicine. PLoS One. 2018;13(11): e0207634.

19. Beech BM, Calles-Escandon J, Hairston KG, Langdon SE, LathamSadler BA, Bell RA. Mentoring programs for underrepresented minority faculty in academic medical centers: a systematic review of the literature. Acad Med. 2013;88(4):541-549.

20. Wingard DL, Garman KA, Reznik V. Facilitating faculty success: outcomes and cost benefit of the UCSD National Center of Leadership in Academic Medicine. Acad Med. 2004;79(suppl 10):S9-S11.

21. Miller AP, Maurer M, Alexander KP. Geriatric cardiology. J Am Coll Cardiol. 2018;71(25):2970-2973.

\section{SUPPORTING INFORMATION}

Additional Supporting Information may be found in the online version of this article.

Supplementary Figure 1. Breakdown of total costs for the CoMPAdRE peer mentorship program.

Supplementary Table 1. Columbia Mentor Peer Aging Research Program compact.

Supplementary Table 2. Curriculum for the first eight CoMPAdRE sessions including themes, topics, exercises, assignments, and faculty speakers. 